\title{
Câmbio e Exportações de Santa Catarina: observações a partir do Plano Real (1994-2018)
}

\author{
Exchange and Exports off Santa Catarina: observations from the Real Plan (1994- \\ 2018)
}

Tipo de Cambio y Exportaciones de Santa Catarina: observaciones del Plan Real (1994-2018)

\author{
Gislene Daiana Martins ${ }^{1}$ \\ https://orcid.org/0000-0003-0871-6778 \\ Isa de Oliveira Rocha ${ }^{2}$ \\ https://orcid.org/0000-0001-9840-0595
}

\begin{abstract}
RESUMO: $O$ artigo analisa a relação entre as taxas médias cambiais anuais e o volume das receitas anuais obtidas por meio das exportações do Estado de Santa Catarina a partir do Plano Real, período de 1994 até 2018. Para tanto utilizou-se pesquisa exploratória e descritiva com abordagem quantitativa realizada por meio de análise documental dos dados relativos às exportações catarinenses no recorte temporal em questão, os quais foram obtidos no portal do Ministério da Economia, Indústria, Comércio Exterior e Serviços - MIDIC, além dos dados das taxas de câmbio do referido período, obtidos no portal do Instituto de Pesquisa Econômica Aplicada (IPEA). Verificou-se neste período analisado (1994-2018) que as diferentes gestões políticas em âmbito nacional desencadearam mudanças de fatores internos como políticas fiscais, monetárias e cambiais, influenciadas também por pressões externas, como as advindas dos organismos de Bretton Woods e das crises financeiras internacionais. No tocante ao comportamento das exportações, observou-se um aumento das receitas provenientes de produtos com baixo valor agregado em detrimento dos produtos de alto valor agregado, o que leva ao entendimento que estejam ocorrendo mudanças no parque fabril catarinense, cujas análises requerem estudos empíricos mais aprofundados.
\end{abstract}

PALAVRAS-CHAVE: Taxas de câmbio. Exportações. Santa Catarina.

ABSTRACT: This research analyzes the relationship between the annual average exchange rates and the volume of annual revenues obtained through exports from the State of Santa Catarina from the Real Plan, covering the years 1994 to 2018. For this analysis, exploratory and descriptive research with a quantitative approach carried out by means of documentary analysis of data related to Santa Catarina's exports in the time period in question, which were obtained from the portal of the Ministry of Economy, Industry, Foreign Trade and Services - MIDIC, in addition to the exchange rate data for that

\footnotetext{
1 Doutoranda em Contabilidade e Finanças pela Universidade Federal do Paraná. E-mail: gislenedaiana@gmail.com.

${ }^{2}$ Doutora em Geografia Humana pela Universidade de São Paulo - USP. Professora da Universidade do Estado de Santa Catarina - UDESC. E-mail: isa.rocha2007@gmail.com.
} 
period, obtained from the IPEA Institute of Applied Economic Research website. It was verified during this period (1994-2018) that the different political administrations at national level triggered changes of internal factors such as fiscal, monetary and exchange policies, also influenced by external pressures, such as the Bretton Woods organisms and the financial crises countries. Regarding export behavior, there was an increase in revenues from low value-added products to the detriment of high valueadded products, which leads to the understanding that changes are taking place in the Santa Catarina manufacturing complex, whose analyzes require more empirical studies.

KEYWORDS: Exchange rates. Exports. Santa Catarina.

RESUMEN: Esta investigación analiza la relación entre los tipos de cambio medios anuales y los ingresos anuales obtenidos de exportaciones del Estado de Santa Catarina del Plan Real, que abarcan los años 1994 a 2018. Para este análisis, a una investigación descriptiva y exploratoria con un enfoque cuantitativo mediante el análisis documental de los datos relacionados con las exportaciones de Santa Catarina en el corte temporal en cuestión, que se obtuvieron del portal del Ministerio de Economía, Industria, Comercio Exterior y Servicios - MIDIC, además de los datos del tipo de cambio para ese período, obtenidos del sitio web del Instituto de Investigación Económica Aplicada (IPEA). Durante este periodo (1994-2018) se verificó que las diferentes administraciones políticas a nivel nacional desencadenaron cambios de factores internos como las políticas fiscales, monetarias y cambiarias, también influenciadas por presiones externas, como los organismos de Bretton Woods y las crisis financieras. Países con respecto al comportamiento de las exportaciones, hubo un aumento en los ingresos por productos de bajo valor agregado en detrimento de los productos de alto valor agregado, lo que lleva a comprender que se están produciendo cambios en el complejo de manufactura de Santa Catarina, cuyos análisis requieren más estudios empíricos.

PALABRAS-CLAVE: Tipos de cambio. Exportaciones. Santa Catarina.

\section{INTRODUÇÃO'}

As taxas de câmbio representam um fator importante na competitividade externa dos países. Tomando por base a moeda norte-americana, preponderantemente utilizada no comércio internacional, sua sobrevalorização estimula as exportações, tendo em vista que os preços dos produtos se tornam sobrevalorizados em dólar, o que consequentemente aumenta a oferta desses. Do mesmo modo, quando a referida moeda está subvalorizada, estimulam-se as importações, em função de haver uma subvalorizarão dos preços dos produtos, aumentando a demanda destes (DEPARTAMENTO INTERSINDICAL DE ESTATÍ́STICA E ESTUDOS SOCIOECONÔMICOS, 2006). Portanto, o controle do câmbio é um dos objetos importantes do comércio internacional.

Diante dos aspectos apresentados, torna-se importante a promoção de políticas cambiais tanto pelas entidades monetárias como pelas entidades governamentais no sentido de controlar o fluxo de capitais e mercadorias, visando, dessa forma, o equilíbrio da balança de comércio exterior. A implementação do Plano Real desencadeou uma paridade da moeda brasileira em relação ao dólar americano, sobretudo no primeiro mandato do expresidente Fernando Henrique Cardoso, mas a partir da segunda gestão houve uma desvalorização gradual do real frente ao dólar até o final de 2018. 
Santa Catarina possui destaque no cenário nacional do comércio exterior, pois a partir da adoção do real sempre esteve entre os 10 maiores estados exportadores nacionais, tendo inclusive permanecido na 5 $5^{\underline{a}}$ posição durante um terço do período de 1994 a 2018, conforme dados do Ministério da Economia, Indústria, Comércio Exterior e Serviços (BRASIL, 2019).

Nesse sentido, o objetivo deste trabalho é verificar a influência da taxa de câmbio nas exportações catarinenses a partir do Plano Real (1994-2018), com a seguinte questão problema: Quais os reflexos das políticas cambiais nas exportações catarinenses após a adoção do Plano Real até o final de 2018?

Para realizar o estudo utilizou-se como metodologia a pesquisa exploratória e descritiva com abordagem quantitativa do tipo documental, quando se efetivou 0 levantamento dos dados das exportações catarinenses obtidos no site do Ministério da Indústria e Comércio Exterior e análise dos dados dessas exportações. As taxas de câmbio foram obtidas no site do Instituto de Pesquisa Econômica Aplicada para o recorte temporal delimitado na pesquisa: 1994-2018.

Santa Catarina é um dos três estados brasileiros que compõem a Região Sul (Figura 1) e apresenta $95.730,684$ quilômetros quadrados de área conforme IBGE (2020). Apesar do território pequeno, comparativamente aos demais estados meridionais, representa a sexta maior economia do país, com PIB de R \$277,2 bilhões em 2017.

Figura 1 - Localização de Santa Catarina

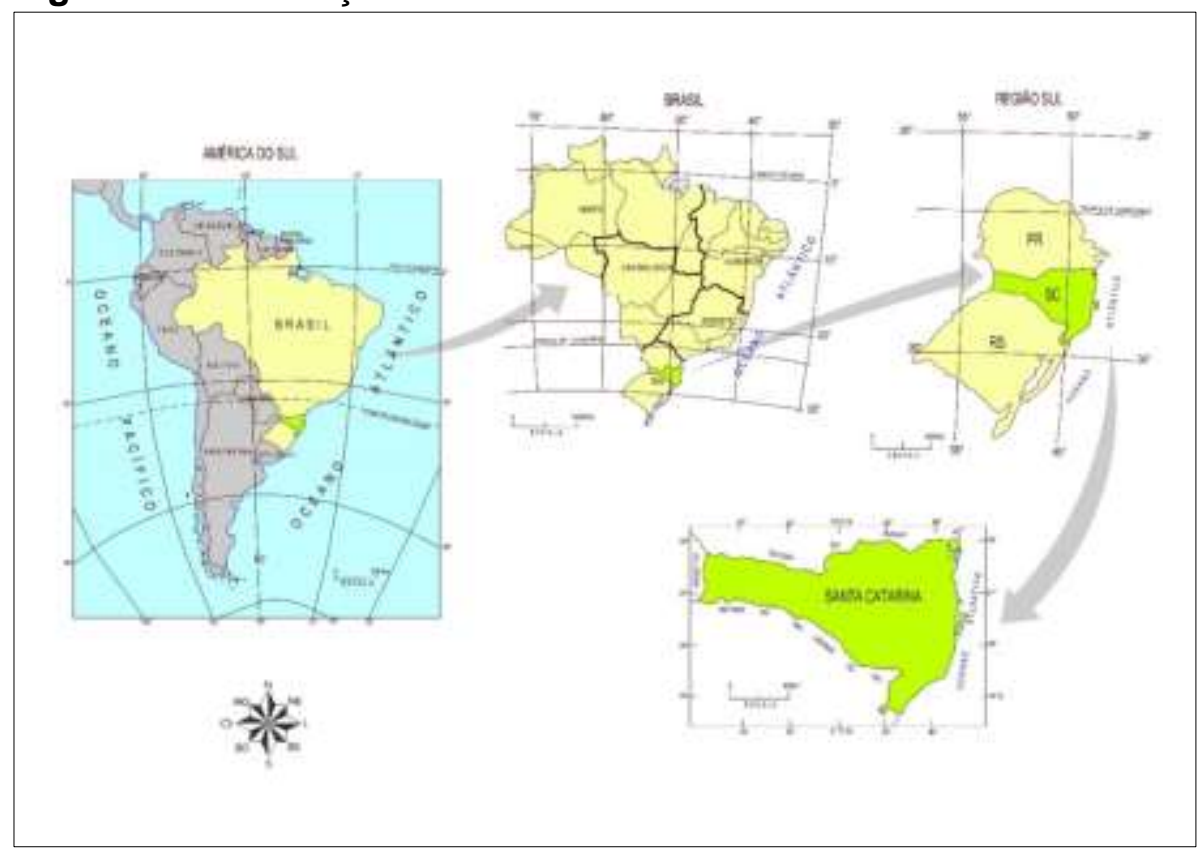

Fonte: Santa Catarina (2016). 
Em função da importância do estado na economia brasileira, torna-se relevante analisar a evolução do perfil do comércio exterior catarinense por meio da relação entre taxa de câmbio e exportações nas diferentes conjunturas políticas vivenciadas pelo país, desde o advento do Plano Real na gestão do ex-presidente Fernando Henrique Cardoso (1994), até o final do mandato presidencial de Michel Temer (2018).

\section{CÂMBIO NO BRASIL A PARTIR DO PLANO REAL}

No Brasil, a moeda estrangeira mais negociada é o dólar dos Estados Unidos, fazendo com que a cotação comumente utilizada seja a dessa moeda. Assim, quando dizemos, por exemplo, que a taxa de câmbio é $R \$ 1,80$, significa que um dólar dos Estados Unidos custa $\mathrm{R} \$ 1,80$ (um real e oitenta centavos). A taxa de câmbio reflete, dessa forma, o custo de uma moeda em relação à outra. As cotações apresentam taxas para a compra e para a venda da moeda, as quais são referenciadas do ponto de vista do agente autorizado a operar no mercado de câmbio pelo Banco Central (BANCO CENTRAL DO BRASIL, 2019).

De forma geral, há basicamente dois tipos básicos de regime cambial: o flexível ou flutuante e o de taxas fixas. No primeiro, a taxa de câmbio é determinada pelo mercado, do mesmo modo que o preço de uma mercadoria qualquer; já no segundo a fixação da taxa de câmbio é administrada pelas autoridades monetárias, no caso brasileiro pelo Banco Central.

O Brasil, a partir da primeira gestão do governo Fernando Henrique Cardoso (FHC), adotou o regime de câmbio fixo, justamente pela política de controle inflacionária implantada no referido governo, e houve uma relativa paridade entre o real e o dólar naquele contexto. A partir de 1999 até os dias atuais (aqui representado pelo final da gestão do governo Temer), o país trabalha com o regime de câmbio flutuante, em função da oscilação do dólar naquele cenário provocado pela deficiência de reservas de dólares esvaziadas no país em virtude da crise cambial estabelecida.

\section{Câmbio no Governo FHC}

A partir da adoção do Plano Real, julho de 1994, o país passou por um período de paridade monetária do real frente ao dólar que perdurou até o final de 1998. Desde o início do Plano Real e durante a primeira gestão de Fernando Henrique Cardoso (FHC), de 1995 a 1998, verifica-se expressiva valorização do real conforme exposto na tabela 1 com dados do Instituto de Pesquisa Econômica Aplicada (2019). Na segunda gestão FHC (1999-2002) houve a gradual desvalorização do real frente ao dólar, dobrando nos dois primeiros anos e triplicando ao final do mandato. O governo FHC caracterizou-se pelo controle da inflação, 
mas por meio de recessão e desemprego, abertura descontrolada do mercado ao capital externo e privatizações de estratégicas corporações estatais brasileiras.

Tabela 1 - Taxas de Câmbio no governo FHC

\begin{tabular}{c|c|c|c|c|c|c|c|c|c|c|c|c|c}
\hline Período & Jan & Fev & Mar & Abr & Mai & Jun & Jul & Ago & Set & Out & Nov & Dez & Média \\
\hline 1994 & & & & & & & 0,93 & 0,9 & 0,87 & 0,85 & 0,84 & 0,85 & $\mathbf{0 , 8 7}$ \\
\hline $\mathbf{1 9 9 5}$ & 0,85 & 0,84 & 0,89 & 0,91 & 0,9 & 0,91 & 0,93 & 0,94 & 0,95 & 0,96 & 0,96 & 0,97 & $\mathbf{0 , 9 2}$ \\
\hline $\mathbf{1 9 9 6}$ & 0,97 & 0,98 & 0,99 & 0,99 & 1 & 1 & 1,01 & 1,01 & 1,02 & 1,03 & 1,03 & 1,04 & $\mathbf{1 , 0 0}$ \\
\hline $\mathbf{1 9 9 7}$ & 1,04 & 1,05 & 1,06 & 1,06 & 1,07 & 1,07 & 1,08 & 1,09 & 1,09 & 1,1 & 1,11 & 1,11 & $\mathbf{1 , 0 7}$ \\
\hline $\mathbf{1 9 9 8}$ & 1,12 & 1,13 & 1,13 & 1,14 & 1,15 & 1,15 & 1,16 & 1,17 & 1,18 & 1,19 & 1,19 & 1,21 & $\mathbf{1 , 1 6}$ \\
\hline $\mathbf{1 9 9 9}$ & 1,5 & 1,91 & 1,9 & 1,69 & 1,68 & 1,77 & 1,8 & 1,88 & 1,9 & 1,97 & 1,93 & 1,84 & $\mathbf{1 , 8 1}$ \\
\hline $\mathbf{2 0 0 0}$ & 1,8 & 1,78 & 1,74 & 1,77 & 1,83 & 1,81 & 1,8 & 1,81 & 1,84 & 1,88 & 1,95 & 1,96 & $\mathbf{1 , 8 3}$ \\
\hline $\mathbf{2 0 0 1}$ & 1,95 & 2 & 2,09 & 2,19 & 2,3 & 2,38 & 2,47 & 2,51 & 2,67 & 2,74 & 2,54 & 2,36 & $\mathbf{2 , 3 5}$ \\
\hline $\mathbf{2 0 0 2}$ & 2,38 & 2,42 & 2,35 & 2,32 & 2,48 & 2,71 & 2,93 & 3,11 & 3,34 & 3,81 & 3,58 & 3,63 & $\mathbf{2 , 9 2}$ \\
\hline
\end{tabular}

Fonte: Instituto de Pesquisa Econômica Aplicada (2019).

Conforme Rezende (2009) a política cambial do governo FHC teve dois regimes de câmbio, no primeiro mandato o regime de câmbio semifixo e no segundo mandato o câmbio flutuante necessário para ajustar a balança comercial, porém perdendo o seu controle sobre a inflação. Entretanto, foi preciso uma política monetária restritiva de altas taxas de juros para atrair capitais externos para manter o regime de bandas cambiais no primeiro mandato e para controlar a inflação no segundo mandato, já que a taxa de câmbio não cumpria mais essa função. $O$ autor enfatiza ainda que o presidente aprofundou a abertura comercial e financeira para os capitais externos entrarem e saírem do país e tratou os investimentos externos nas mesmas condições que o capital nacional, prejudicando dessa forma a competitividade do capital nacional. Além disso, privatizou empresas estatais como Embraer, Telebrás, Vale do Rio Doce e inúmeros bancos estaduais desfazendo-se de boa parte dos ativos brasileiros que trariam uma rentabilidade maior no longo prazo do que a receita auferida com a venda deles no presente.

Com FHC o endividamento público aumentou e não se conseguiu controlar os gastos para gerar investimento, mesmo com as privatizações, provocando a desestruturação de vários setores produtivos e enormes déficits nas contas públicas.

\section{Câmbio no Governo Lula}

Segundo Morais e Saad Filho (2011), o governo Lula (2003 - 2010) manteve o câmbio flutuante dentre suas ações macroeconômicas aliadas ainda a política monetária determinada pelas metas de inflação e política fiscal visando a manutenção do superávit primário como forma de compensar o déficit recorrente das contas públicas. 
O governo Lula adotou uma perspectiva de governo desenvolvimentista, ou como mencionam alguns autores, neo-desenvolvimentista. Segundo Bresser-Pereira (2006) os objetivos do desenvolvimentismo ou neo-desenvolvimentismo caracterizam-se pela complementaridade entre as políticas monetária, fiscal, cambial e salarial para influenciar as variáveis econômicas como as taxas de juros, as taxas de câmbio, as taxas de inflação e salários, ou seja, caracterizam-se por políticas com objetivos múltiplos, e não apenas pela estabilidade monetária prerrogativa das políticas neoliberais.

Em relação especificamente às taxas de câmbio, objeto de análise deste trabalho, observa-se uma valorização gradual da moeda brasileira frente ao dólar do início do primeiro mandato de Lula até o final do segundo conforme observado na tabela 2.

Tabela 2 - Taxas de Câmbio no governo Lula

\begin{tabular}{c|c|c|c|c|c|c|c|c|c|c|c|c|c}
\hline Período & Jan & Fev & Mar & Abr & Mai & Jun & Jul & Ago & Set & Out & Nov & Dez & Média \\
\hline $\mathbf{2 0 0 3}$ & 3,44 & 3,59 & 3,45 & 3,12 & 2,96 & 2,88 & 2,88 & 3 & 2,92 & 2,86 & 2,91 & 2,93 & $\mathbf{3 , 0 8}$ \\
\hline $\mathbf{2 0 0 4}$ & 2,85 & 2,93 & 2,91 & 2,91 & 3,1 & 3,13 & 3,04 & 3 & 2,89 & 2,85 & 2,79 & 2,72 & $\mathbf{2 , 9 3}$ \\
\hline $\mathbf{2 0 0 5}$ & 2,69 & 2,6 & 2,7 & 2,58 & 2,45 & 2,41 & 2,37 & 2,36 & 2,29 & 2,26 & 2,21 & 2,29 & $\mathbf{2 , 4 3}$ \\
\hline $\mathbf{2 0 0 6}$ & 2,27 & 2,16 & 2,15 & 2,13 & 2,18 & 2,25 & 2,19 & 2,16 & 2,17 & 2,15 & 2,16 & 2,15 & $\mathbf{2 , 1 8}$ \\
\hline $\mathbf{2 0 0 7}$ & 2,14 & 2,1 & 2,09 & 2,03 & 1,98 & 1,93 & 1,88 & 1,97 & 1,9 & 1,8 & 1,77 & 1,79 & $\mathbf{1 , 9 5}$ \\
\hline $\mathbf{2 0 0 8}$ & 1,77 & 1,73 & 1,71 & 1,69 & 1,66 & 1,62 & 1,59 & 1,61 & 1,8 & 2,17 & 2,27 & 2,39 & $\mathbf{1 , 8 3}$ \\
\hline $\mathbf{2 0 0 9}$ & 2,31 & 2,31 & 2,31 & 2,21 & 2,06 & 1,96 & 1,93 & 1,85 & 1,82 & 1,74 & 1,73 & 1,75 & $\mathbf{2 , 0 0}$ \\
\hline $\mathbf{2 0 1 0}$ & 1,78 & 1,84 & 1,79 & 1,76 & 1,81 & 1,81 & 1,77 & 1,76 & 1,72 & 1,69 & 1,71 & 1,69 & $\mathbf{1 , 7 6}$ \\
\hline
\end{tabular}

Fonte: Instituto de Pesquisa Econômica Aplicada (2019).

Verifica-se na tabela 2 uma redução gradativa e significativa e uma relativa valoração da moeda brasileira frente à norte-americana. No final do segundo mandato do governo Lula a taxa média cambial brasileira fechou em torno $R \$ 1,76$, ou seja, inferior àquela de fechamento do segundo mandato do governo FHC, que havia fechado em torno de \$2,92 em média. A análise da taxa de fechamento do mês de dezembro, ou seja, os meses referentes ao final de cada gestão presidencial, revela que a diferença é ainda mais acentuada no tocante à taxa cambial. No governo $\mathrm{FHC}$ ficou em $\mathrm{R} \$ 3,63$ enquanto que a do governo Lula fechou em $R \$ 1,69$, conforme as tabelas 1 e 2 .

De acordo com Rezende (2009) a desvalorização cambial herdada do governo anterior ajudou as exportações a crescerem durante o início do novo governo, fazendo com que a balança comercial batesse recorde em 2003. O mercado percebeu que o governo eleito estava compromissado em garantir a estabilidade monetária, diminuiu sua especulação financeira e voltou a dar estabilidade ao câmbio. Esses dois fatores fizeram com que a taxa de câmbio apresentasse uma tendência à valorização e, segundo o Boletim do Banco Central de 2003, a taxa de câmbio passou de $R \$ 3,52$ em janeiro para $R \$ 2,88$ em abril de 2003, próxima a de equilíbrio industrial. 


\section{Câmbio no Governo Dilma}

Segundo Bresser-Pereira (2013) a presidente Dilma Rousseff iniciou seu mandato presidencial com uma proposta de continuidade do governo Lula, combinando taxas relativamente elevadas de crescimento com redução da desigualdade econômica. No seu mandato, a taxa de juros caiu para cerca de $3 \%$ ao ano, e a taxa de câmbio se depreciou de $R \$ 1,65$ para cerca de $R$ \$2,05 por dólar do início até metade do mandato. Tais mudanças, especialmente a relativa à taxa de câmbio, estão longe de serem suficientes. A taxa de câmbio competitiva ou "de equilíbrio industrial" no Brasil é de cerca de $R$ \$2,75 por dólar, conforme demonstrou Marconi, Araújo e Oreiro (2015), de forma que a indústria brasileira não saiu de sua condição de crise e de desindustrialização.

Em relação especificamente às taxas de câmbio, conforme se pode observar na tabela 3 , houve um relativo aumento em média, favorecendo desse modo a questão da taxa de câmbio competitiva ou de equilíbrio industrial até o final de 2014, conforme mencionaram Marconi Araújo e Oreiro (2015), favorecendo nesse sentido a industrialização, bem como as exportações brasileiras naquele cenário. A partir de então, houve uma desvalorização razoável da moeda brasileira em relação ao dólar americano, tendo em média no último período de mandato alcançado quase $R \$ 3,60$ e fechando em $R \$ 3,21$ no último mês de seu mandato oficial quando ocorreu o impeachment.

Tabela 3 - Taxas de Câmbio no governo Dilma

\begin{tabular}{c|c|c|c|c|c|c|c|c|c|c|c|c|c}
\hline Período & Jan & Fev & Mar & Abr & Mai & Jun & Jul & Ago & Set & Out & Nov & Dez & Média \\
\hline 2011 & 1,67 & 1,67 & 1,66 & 1,59 & 1,61 & 1,59 & 1,56 & 1,6 & 1,75 & 1,77 & 1,79 & 1,84 & $\mathbf{1 , 6 7}$ \\
\hline 2012 & 1,79 & 1,72 & 1,8 & 1,85 & 1,99 & 2,05 & 2,03 & 2,03 & 2,03 & 2,03 & 2,07 & 2,08 & $\mathbf{1 , 9 6}$ \\
\hline 2013 & 2,03 & 1,97 & 1,98 & 2 & 2,03 & 2,17 & 2,25 & 2,34 & 2,27 & 2,19 & 2,3 & 2,35 & $\mathbf{2 , 1 6}$ \\
\hline 2014 & 2,38 & 2,38 & 2,33 & 2,23 & 2,22 & 2,24 & 2,22 & 2,27 & 2,33 & 2,45 & 2,55 & 2,64 & $\mathbf{2 , 3 5}$ \\
\hline 2015 & 2,63 & 2,82 & 3,14 & 3,04 & 3,06 & 3,11 & 3,22 & 3,51 & 3,91 & 3,88 & 3,78 & 3,87 & $\mathbf{3 , 3 3}$ \\
\hline 2016 & 4,05 & 3,97 & 3,7 & 3,57 & 3,54 & 3,42 & 3,28 & 3,21 & & & & & $\mathbf{3 , 5 9}$ \\
\hline
\end{tabular}

Fonte: Instituto de Pesquisa Econômica Aplicada (2019).

Para Bresser-Pereira (2013) o governo Dilma teve dificuldade em promover a desvalorização necessária da taxa de câmbio em função de conflitos de interesses. Primeiramente porque o poder dos exportadores de commodities estava impedindo a imposição de um imposto variável sobre suas exportações que permitisse que a taxa de câmbio se aproximasse do nível de equilíbrio industrial. Segundo, porque o governo temia o aumento da inflação decorrente da depreciação. Terceiro, porque temia as consequências impopulares da redução dos salários que ocorreria no curto prazo, embora fosse temporária, pois com o aumento dos investimentos e do crescimento os salários passariam a aumentar 
consequentemente. $\mathrm{E}$, finalmente, porque bancos e empresas endividadas em moeda forte não querem ouvir falar de desvalorização cambial.

De acordo com Dweck e Teixeira (2019), nos governos Lula e Dilma a política fiscal atuou em direção a garantir a geração de emprego. Nesse sentido houve uma queda constante da taxa de desemprego, levando a aumentos constantes dos salários reais nos referidos mandatos.

\section{Câmbio no Governo Temer}

De acordo com Prates, Fritz e Paula (2018) no governo Temer foram adotadas alterações significativas na política econômica, sobretudo no tocante do reforço do tripé de política econômica mencionado anteriormente. Em relação à política cambial, essa se aproximou de um regime de flutuação limpa, ou seja, com menos intervenções do BCB (Banco Central do Brasil) e a política monetária se tornou mais conservadora até o primeiro trimestre de 2017.

Na gestão Temer, que perdurou de agosto de 2016 a dezembro de 2018, observou-se taxas cambiais semelhantes aos dois últimos anos do governo Dilma, conforme tabela 4. Não houve, todavia, uma preocupação com o desenvolvimento industrial do país, sendo sua gestão marcada por uma "[...] inflexão na experiência desenvolvimentista recente e contribuindo para intensificar a crise brasileira" naquele cenário (PRATES; FRITZ; PAULA, 2018, p. 25).

Tabela 4 - Taxas de Câmbio no governo Temer

\begin{tabular}{c|c|c|c|c|c|c|c|c|c|c|c|c|c}
\hline Período & Jan & Fev & Mar & Abr & Mai & Jun & Jul & Ago & Set & Out & Nov & Dez & Média \\
\hline 2016 & & & & & & & & & 3,26 & 3,19 & 3,34 & 3,35 & $\mathbf{3 , 2 8}$ \\
\hline 2017 & 3,2 & 3,1 & 3,13 & 3,14 & 3,21 & 3,3 & 3,21 & 3,15 & 3,13 & 3,19 & 3,26 & 3,29 & $\mathbf{3 , 1 9}$ \\
\hline 2018 & 3,21 & 3,24 & 3,28 & 3,41 & 3,64 & 3,77 & 3,83 & 3,93 & 4,12 & 3,76 & 3,79 & 3,89 & $\mathbf{3 , 6 6}$ \\
\hline
\end{tabular}

Fonte: Instituto de Pesquisa Econômica Aplicada (2019).

\section{EXPORTAÇÕES CATARINENSES E SUA RELAÇÃO COM O CÂMBIO}

Em relação à composição das exportações, no Brasil as mesmas são classificadas e contabilizadas por fatores agregados, ou seja, por produtos básicos e por produtos industrializados, sendo estes últimos por sua vez compostos pelo conjunto de produtos manufaturados e semimanufaturados.

Observa-se para Santa Catarina, no período 1994-2018, crescimento gradual das exportações tanto em termos numéricos de produtos básicos quanto de produtos industrializados. Porém, ao analisar o comportamento em termos percentuais, é possível 
notar que tais conjuntos crescem em diferentes proporções ao longo do tempo. Em termos percentuais as exportações de produtos básicos aumentam, ao passo que as de produtos industrializados decrescem, de maneira geral, denotando uma mudança de perfil do dinamismo industrial catarinense no recorte temporal analisado. Ou seja, não há uma preocupação relevante na questão do desenvolvimento industrial da produção brasileira, que seria um aspecto importante no processo de crescimento da economia do país como um todo.

De acordo com Mortatti, Miranda e Bacchi (2011, p. 313), "[...] nos últimos anos, o Brasil tornou-se importador de equipamentos industrializados, manufaturados e um exportador de commodities, como grãos de soja e minério de ferro", ou seja, exportador de produtos de baixo valor agregado e importador de produtos de alto valor agregado. Tal fato pode ser observado na tabela 5. Carvalho e Silva (2008) alertam que o declínio da exportação de manufaturados e o maior crescimento do comércio de produtos básicos indicam uma tendência à desindustrialização do país, e esta por sua vez é resultante do crescimento acelerado das exportações de recursos naturais.

Tabela 5 - Exportações Catarinenses por Fatores Agregados - milhões US\$ (1994-2018)

\begin{tabular}{c|c|c|c|c|c}
\hline ANO & Total US\$ & Básicos US\$ & Percentual & Industrializados & Percentual \\
\hline $\mathbf{1 9 9 4}$ & 2.405 & 731 & $30 \%$ & 1.674 & $70 \%$ \\
\hline $\mathbf{1 9 9 5}$ & 2.652 & 788 & $30 \%$ & 1.864 & $70 \%$ \\
\hline $\mathbf{1 9 9 6}$ & 2.637 & 914 & $35 \%$ & 1.723 & $65 \%$ \\
\hline $\mathbf{1 9 9 7}$ & 2.806 & 889 & $32 \%$ & 1.917 & $68 \%$ \\
\hline $\mathbf{1 9 9 8}$ & 2.605 & 772 & $30 \%$ & 1.833 & $70 \%$ \\
\hline $\mathbf{1 9 9 9}$ & 2.567 & 683 & $27 \%$ & 1.884 & $73 \%$ \\
\hline $\mathbf{2 0 0 0}$ & 2.712 & 695 & $26 \%$ & 2.017 & $74 \%$ \\
\hline $\mathbf{2 0 0 1}$ & 3.031 & 1.003 & $33 \%$ & 2.028 & $67 \%$ \\
\hline $\mathbf{2 0 0 2}$ & 3.160 & 970 & $31 \%$ & 2.190 & $69 \%$ \\
\hline $\mathbf{2 0 0 3}$ & 3.701 & 1.053 & $28 \%$ & 2.648 & $72 \%$ \\
\hline $\mathbf{2 0 0 4}$ & 4.862 & 1.463 & $30 \%$ & 3.399 & $70 \%$ \\
\hline $\mathbf{2 0 0 5}$ & 5.594 & 1.839 & $33 \%$ & 3.755 & $67 \%$ \\
\hline $\mathbf{2 0 0 6}$ & 5.982 & 1.750 & $29 \%$ & 4.232 & $71 \%$ \\
\hline $\mathbf{2 0 0 7}$ & 7.381 & 2.670 & $36 \%$ & 4.711 & $64 \%$ \\
\hline $\mathbf{2 0 0 8}$ & 8.331 & 3.300 & $40 \%$ & 5.031 & $60 \%$ \\
\hline $\mathbf{2 0 0 9}$ & 6.427 & 2.834 & $44 \%$ & 3.593 & $56 \%$ \\
\hline $\mathbf{2 0 1 0}$ & 7.582 & 3.267 & $43 \%$ & 4.310 & $57 \%$ \\
\hline $\mathbf{2 0 1 1}$ & 9.051 & 4.128 & $46 \%$ & 4.916 & $54 \%$ \\
\hline $\mathbf{2 0 1 2}$ & 8.921 & 4.113 & $46 \%$ & 4.800 & $54 \%$ \\
\hline $\mathbf{2 0 1 3}$ & 8.689 & 3.957 & $46 \%$ & 4.726 & $54 \%$ \\
\hline $\mathbf{2 0 1 4}$ & 8.987 & 4.162 & $46 \%$ & 4.820 & $54 \%$ \\
\hline $\mathbf{2 0 1 5}$ & 7.644 & 3.377 & $44 \%$ & 4.264 & $56 \%$ \\
\hline $\mathbf{2 0 1 6}$ & 7.593 & 3.263 & $43 \%$ & 4.328 & $57 \%$ \\
\hline $\mathbf{2 0 1 7}$ & 8.511 & 3.584 & $42 \%$ & 4.923 & $58 \%$ \\
\hline $\mathbf{2 0 1 8}$ & 8.948 & 3.993 & $45 \%$ & 4.950 & $55 \%$ \\
\hline $\mathbf{F}$ & & & &
\end{tabular}

Fonte: Brasil (2019). 
Carvalho e Silva (2008) enfatizam que houve uma piora na qualidade das exportações brasileiras e isso é observado também em Santa Catarina, conforme tabela 5. Afirmam ainda que o processo de desindustrialização vitimou também o agronegócio brasileiro, que passou a concentrar a exportação em produtos com menor valor agregado.

\section{Principais Produtos Exportados de Santa Catarina}

Durante o governo $\mathrm{FHC}$ o carro chefe das exportações catarinenses foram os motocompressores herméticos correspondendo a cerca de $10 \%$ das exportações tanto em 1995 quanto no ano 2000, conforme pode ser observado na tabela 6 elaborada com base em Rocha (2004).

Tabela 6 - Principais Produtos exportados por SC em 1995 e 2000

Principais produtos exportados de Santa Catarina - 1995 e 2000 - milhões US\$ FOB

\begin{tabular}{l|c|c}
\hline Produtos & Valores & $\%$ Total \\
\hline Motocompressores herméticos & 263 & $9,9 \%$ \\
\hline Pedaços e miúdos de frango & 217 & $8,2 \%$ \\
\hline Resíduos sólidos extraídos do óleo de soja & 183 & $6,9 \%$ \\
\hline Roupas e artigos têxteis & 124 & $4,7 \%$ \\
\hline Carne de frango não cortada em pedaços & 124 & $4,7 \%$ \\
\hline
\end{tabular}

Fonte: Rocha (2004).

O segundo produto com maior expressão nas exportações de Santa Catarina foram as carnes de frango nos anos de 1995 e 2000. Nesse período observa-se que a produção de produtos manufaturados ainda tinha um peso forte nas exportações catarinenses, pois corresponderam aos principais produtos exportados tanto em 1995 quanto em 2000, conforme pode ser observado na tabela 6 . Nota-se também a presença de uma indústria de produção e abate de carnes relevante no estado, pois este segmento se manteve acompanhando a segunda maior representação das exportações catarinenses nos dois anos analisados, 1995 e 2000. Esse setor industrial sofreu avanço tecnológico, bem como aumento de demanda destes produtos por países externos, sobretudo na China, o que acarretou uma mudança de comportamento das exportações catarinenses a partir das gestões presidenciais de Lula, Dilma e Temer.

A partir da gestão Lula notou-se de fato a mudança do perfil dos produtos exportados, e as carnes, de maneira geral (tabelas 7 e 8), sobretudo de aves, passaram a liderar 0 ranking das exportações catarinenses até os dias atuais. Uma das razões para este fato, de acordo com Barenho (2017), é que a China mantinha seu processo de crescimento 
econômico acelerado, o que impulsionava a demanda por commodities de mercados emergentes, incluídos aqui o Brasil.

Tabela 7 - Principais Produtos exportados por SC em 2005 Principais produtos exportados de Santa Catarina - 2005 - milhões US\$ FOB

\begin{tabular}{l|c|c}
\hline Produtos & Valores & $\%$ Total \\
\hline Frango (carnes e miudezas) & 426 & $7,6 \%$ \\
\hline Suíno (carnes, carcaças e miudezas) & 244 & $4,4 \%$ \\
\hline Móveis de madeira & 200 & $3,6 \%$ \\
\hline Motocompressor hermético & 172 & $3,1 \%$ \\
\hline Motores e geradores elétrico & 113 & $2,0 \%$ \\
\hline
\end{tabular}

Fonte: CLICKRBS (2019).

Tabela 8 - Principais produtos exportados de Santa Catarina - 2010

\begin{tabular}{l|c|c}
\hline \multicolumn{3}{c}{ Principais produtos exportados de Santa Catarina - 2010 milhões US\$ FOB } \\
\hline Produtos & Valores & $\%$ Total \\
\hline Carnes e Pescados & 2.583 & $34,10 \%$ \\
\hline Fumo & 873 & $11,50 \%$ \\
\hline Motores bombas e compressores & 589 & $7,80 \%$ \\
\hline Geradores, transformadores e motores elétricos & 553 & $7,30 \%$ \\
\hline Acessórios para veículos & 414 & $5,50 \%$ \\
\hline
\end{tabular}

Fonte: Apex Brasil (2011).

No governo Dilma, durante o primeiro mandato, permaneceu essa tendência das exportações de carnes preponderantemente de frangos, seguidas pela categoria fumo e soja, conforme tabela 9.

Tabela 9 - Principais produtos exportados de Santa Catarina - 2013

\begin{tabular}{l|c|c}
\hline \multicolumn{3}{c}{ Principais produtos exportados de Santa Catarina - 2013 - milhões US\$ FOB } \\
\hline Produtos & Valores & $\%$ Total \\
\hline Frango pedaços e miudezas congelados & 1.333 & $15,3 \%$ \\
\hline Fumo não manufaturado-virgínia & 768 & $8,8 \%$ \\
\hline Soja, mesmo triturada, & 481 & $5,5 \%$ \\
\hline Motocompressor & 407 & $4,7 \%$ \\
\hline Blocos de cilindros para motores diesel & 392 & $4,5 \%$ \\
\hline
\end{tabular}

Fonte: Federação das Indústrias do Estado de Santa Catarina (2014).

Durante o governo Temer a exportação de carnes manteve-se como carro chefe das exportações catarinenses, conforme tabela 10. A carne de frango continuou liderando a primeira posição no ranking e a carne suína a terceira posição; entre estes, aparece a soja na segunda posição que veio alcançando fatias no comercio exterior catarinense. Tal fato evidencia a tendência do estado ao agronegócio nos dias atuais e uma mudança de comportamento em relação ao perfil exportador catarinense. Espíndola (2018) mencionou que a partir de 1990 houve em Santa Catarina um processo de reestruturação produtiva 
bem como na economia brasileira. O estado perdeu participação em alguns mercados e adentrou em outros e tal fato pode ser observado ao verificar-se o perfil dos cinco principais produtos exportados no estado, de 1995 a 2018, conforme constatado nas tabelas 6 a 10.

Tabela 10 - Principais produtos exportados de Santa Catarina - 2018 Principais produtos exportados de Santa Catarina - 2018- milhões US\$ FOB

\begin{tabular}{l|c|c}
\hline Produtos & Valores & $\%$ Total \\
\hline Carne de Frango congelada incluindo miúdos & 1.550 & 17 \\
\hline Soja mesmo triturada & 930 & 10 \\
\hline Carne Suína congelada & 570 & 6,3 \\
\hline Motores, geradores, transformadores elétricos e partes & 500 & 5,6 \\
\hline Motores para veículos automóveis e partes & 430 & 4,8 \\
\hline
\end{tabular}

Fonte: Brasil (2019).

\section{Influência do câmbio nas exportações catarinenses}

Conforme tabela 11, Santa Catarina tem evoluído em termos de receita oriundas das exportações, com algumas depressões que ocorreram durante o segundo mandato do governo FHC, porém voltando a crescer progressivamente durante os dois mandatos do governo Lula, salvo nos dois últimos anos da segunda gestão. Tal fato pode ser explicado pelos reflexos da crise internacional ocorrida entre 2008 e 2010 oriundo da bolha imobiliária nos Estados Unidos.

Tabela 11 - Participação das exportações catarinenses no Brasil (1994-2018) - milhões US\$ FOB (1994-2018)

\begin{tabular}{|c|c|c|c|c|c|c|c|}
\hline ANO & $\begin{array}{l}\text { Exportações } \\
\text { Catarinenses }\end{array}$ & $\begin{array}{c}\text { Participação } \\
\text { SC \% }\end{array}$ & $\begin{array}{l}\text { Posição } \\
\text { SC/Brasil }\end{array}$ & ANO & $\begin{array}{l}\text { Exportações } \\
\text { Catarinenses }\end{array}$ & $\begin{array}{c}\text { Participação } \\
\text { SC \% }\end{array}$ & $\begin{array}{l}\text { Posição } \\
\text { SC/Brasil }\end{array}$ \\
\hline 1994 & 2.405 & 5,5 & $5^{\mathrm{a}}$ & 2007 & 7.381 & 4,6 & $7^{\underline{a}}$ \\
\hline 1995 & 2.652 & 5,7 & 6a & 2008 & 8.331 & 4,2 & $9^{a}$ \\
\hline 1996 & 2.637 & 5,5 & $5^{\mathrm{a}}$ & 2009 & 6.427 & 4,2 & $10^{\mathrm{a}}$ \\
\hline 1997 & 2.806 & 5,3 & $5^{\text {a }}$ & 2010 & 7.582 & 3,7 & $10^{\underline{a}}$ \\
\hline 1998 & 2.605 & 5,1 & $5^{\text {a }}$ & 2011 & 9.051 & 3,5 & $10^{\mathrm{a}}$ \\
\hline 1999 & 2.567 & 5,3 & $5^{\underline{a}}$ & 2012 & 8.921 & 3,7 & $10^{\mathrm{a}}$ \\
\hline 2000 & 2.712 & 4,9 & $6^{\underline{a}}$ & 2013 & 8.689 & 3,6 & $10^{\mathrm{a}}$ \\
\hline 2001 & 3.031 & 5,2 & $5^{\mathrm{a}}$ & 2014 & 8.987 & 4 & $9^{a}$ \\
\hline 2002 & 3.160 & 5,2 & $6^{\underline{a}}$ & 2015 & 7.644 & 4 & $10^{\mathrm{a}}$ \\
\hline 2003 & 3.701 & 5 & $6^{\underline{a}}$ & 2016 & 7.593 & 4,1 & $8^{\underline{a}}$ \\
\hline 2004 & 4.862 & 5 & $6^{\underline{a}}$ & 2017 & 8.511 & 3,9 & $8^{\underline{a}}$ \\
\hline 2005 & 5.594 & 4,7 & $8^{\underline{a}}$ & 2018 & 8.948 & 3,7 & $8^{\underline{a}}$ \\
\hline 2006 & 5.982 & 4,3 & $9^{a}$ & & & & \\
\hline
\end{tabular}

Fonte: Brasil (2019).

O governo Dilma apresentou as maiores receitas oriundas das exportações, de acordo com os dados da tabela 11. No seu primeiro ano de mandato, em 2011, a receita foi a maior dos últimos 15 anos anteriores, conforme tabela 5 . Isso se deve aos reflexos da política 
econômica desenvolvimentista adotada no governo Lula. No final do mandato Dilma, entre 2015 e 2016, as receitas apresentaram uma queda relativa, relacionada com o contexto político e econômico vivenciado pelo país naquele momento. Conforme Prates, Fritz e Paula (2018), esse período foi marcado pela deterioração das condições externas devido à conjunção de fatores como a crise da área do euro, sinalizações de normalização da política monetária nos Estados Unidos e desaceleração da economia chinesa que resultaram na redução dos fluxos de capitais para as economias emergentes, na desaceleração da economia e do comércio globais e na queda dos preços das commodities, diminuindo, consequentemente, o montante das receitas advindas das exportações.

No mandato de Temer as receitas oriundas de exportações voltaram a crescer em função principalmente da retomada do crescimento das economias avançadas e emergentes, corroborada, em grande parte, pelo maior dinamismo do comércio global, que contribuiu para o aumento dos preços das commodities (PRATES; FRITZ; PAULA, 2018).

Quanto à participação das exportações catarinenses em termos de Brasil, verifica-se

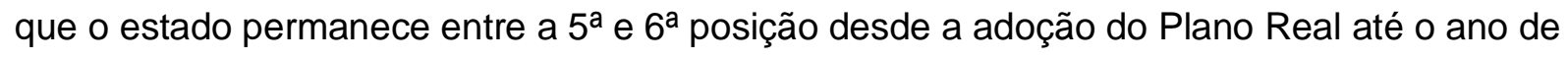
2004, correspondente a metade do primeiro mandato do governo Lula. A partir de então, Santa Catarina alterou suas posições no ranking, situando-se a partir da 7a posição, permanecendo, contudo, sempre entre os 10 maiores estados exportadores do país. $O$ maior exportador brasileiro continua sendo São Paulo, tendo em vista que possui o maior parque industrial do país, seguido dos estados de Minas Gerais, Rio Grande do Sul e Rio de Janeiro, que alternam suas posições no ranking conforme o ano analisado, sendo depois acompanhados pelo Estado do Paraná.

Esse comportamento deve-se a mudança do perfil exportador brasileiro, no sentido de crescimento das exportações de produtos básicos, que vem aumentando em relação aos de maior valor agregado conforme visto anteriormente. Assim, outros estados ganharam posições no ranking a partir do ano de 2005.

Verificando-se as exportações catarinenses comparativamente com a taxa cambial média anual, nota-se conforme tabela 12, que aquelas são diretamente proporcionais a estas até o ano de 2003. A partir de 2004, embora as taxas cambiais apresentem uma queda relativa, as receitas de exportações continuam aumentando até 2008, justamente porque os valores estão próximos da taxa de câmbio competitiva ou "de equilíbrio industrial", ou seja, próximas de $\mathrm{R} \$ 2,75$ até o ano de 2006. Em 2007 e 2008, embora a taxa de câmbio anual tenha ficado um pouco abaixo de $R \$ 2,00$, o volume de exportações catarinenses continuou a crescer em função do ingresso considerável de capitais externos para a economia brasileira propiciado pelo aumento das exportações e dos preços dos produtos de exportação das commodities que cresceram substancialmente. Estes fatores permitiram 
melhora das contas externas, além de forte acúmulo de reservas internacionais segundo Carcanholo et al. (2008).

Tabela 12 - Média das Taxas de Câmbio Anuas X Exportações Catarinenses - milhões US\$ FOB (1994-2018)

\begin{tabular}{r|r|r|r|r|r|r|r|r}
\hline Ano & Câmbio & Exportações & Ano & Câmbio & Exportações & Ano & Câmbio & Exportações \\
\hline $\mathbf{1 9 9 4}$ & 0,87 & 2.405 & $\mathbf{2 0 0 3}$ & 3,08 & 3.701 & $\mathbf{2 0 1 1}$ & 1,68 & 9.051 \\
\hline $\mathbf{1 9 9 5}$ & 0,92 & 2.652 & $\mathbf{2 0 0 4}$ & 2,93 & 4.862 & $\mathbf{2 0 1 2}$ & 1,96 & 8.921 \\
\hline $\mathbf{1 9 9 6}$ & 1,01 & 2.637 & $\mathbf{2 0 0 5}$ & 2,43 & 5.594 & $\mathbf{2 0 1 3}$ & 2,16 & 8.689 \\
\hline $\mathbf{1 9 9 7}$ & 1,08 & 2.806 & $\mathbf{2 0 0 6}$ & 2,18 & 5.982 & $\mathbf{2 0 1 4}$ & 2,35 & 8.987 \\
\hline $\mathbf{1 9 9 8}$ & 1,16 & 2.605 & $\mathbf{2 0 0 7}$ & 1,95 & 7.381 & $\mathbf{2 0 1 5}$ & 3,33 & 7.644 \\
\hline $\mathbf{1 9 9 9}$ & 1,81 & 2.567 & $\mathbf{2 0 0 8}$ & 1,83 & 8.331 & $\mathbf{2 0 1 6}$ & 3,29 & 7.593 \\
\hline $\mathbf{2 0 0 0}$ & 1,83 & 2.712 & $\mathbf{2 0 0 9}$ & 2,00 & 6.427 & $\mathbf{2 0 1 7}$ & 3,19 & 8.511 \\
\hline $\mathbf{2 0 0 1}$ & 2,35 & 3.031 & $\mathbf{2 0 1 0}$ & 1,76 & 7.582 & $\mathbf{2 0 1 8}$ & 3,66 & 8.948 \\
\hline $\mathbf{2 0 0 2}$ & 2,92 & 3.160 & & & & & & \\
\hline
\end{tabular}

Fonte: Instituto de Pesquisa Econômica Aplicada (2019) e Brasil (2019).

No ano de 2009 há um comportamento adverso da relação entre as taxas de câmbio e exportações, ou seja, embora a taxa média cambial anual voltar a crescer, as exportações caíram substancialmente; esse cenário é reflexo da crise financeira internacional desencadeada no final de 2008 nos Estados Unidos, como já mencionado anteriormente.

A partir de 2010 há um período de recuperação econômica pós crise de 2008, que vai até 2014, quando as médias das taxas cambiais anuais e as exportações catarinenses cresceram proporcionalmente ficando próximas novamente da taxa de equilíbrio em 2014.

Entre 2015 e 2016 as taxas de câmbio aumentam razoavelmente acima daquela de equilíbrio e as exportações caem, corroboradas pelo cenário de crise política vivenciados pelo país ao final da gestão do governo Dilma.

A partir de então, em 2017 e 2018, com outro grupo dominando o poder federal, as exportações crescem juntamente com o crescimento das médias das taxas de câmbio, embora relativamente acima da taxa de equilíbrio industrial. Tal fato se dá principalmente pelo crescimento das exportações de produtos básicos ou de baixo valor agregado como os óleos brutos de petróleo, minérios de ferro e seus concentrados, e soja, mesmo triturada, no caso brasileiro. No caso catarinense os principais produtos exportados foram carne de frango congelada fresca ou refrigerada incluindo miúdos, a soja mesmo triturada e a carne suína congelada fresca ou refrigerada respectivamente, nesse último cenário analisado de acordo com os dados do Brasil (2019).

Mamigonian (2018) alerta que, desde o governo FHC, a adoção da âncora cambial levou o país às importações predatórias, que iniciaram uma brutal desindustrialização, em andamento até hoje. $\mathrm{O}$ autor salienta ainda que mesmo nos governos do PT insistiu-se no combate à inflação usando dólar barato, prejudicial à economia nacional, ao invés de 
combatê-la com crescimento. Nesse sentido, é necessário ao país um novo pacto econômico e político e de um novo desenvolvimentismo, assim será possível o crescimento brasileiro na ótica de Rangel (2005) conforme assinalado por Bresser-Pereira (2012).

\section{CONSIDERAÇÕES FINAIS}

Observou-se com este trabalho que há relação entre as taxas de câmbio e as exportações. As exportações crescem proporcionalmente às taxas de câmbio até um certo nível, aproximado do que se chama de equilíbrio industrial, ou seja, $R \$ 2,75$. Quando as taxas cambiais se afastam muito desse parâmetro, há mudança de comportamento das exportações. Como observado na tabela 12, quando a média da taxa de câmbio está tanto em torno de $\mathrm{R} \$ 2,00$ e em torno de $\mathrm{R} \$ 3,00$ o valor adquirido com as exportações se assemelham.

Contudo, há outros fatores que influenciam nessa dinâmica, tanto externos quanto internos. No caso externo destaca-se o contexto internacional da crise financeira global emergida em 2008 nos Estados Unidos, que afetou a economia dos países, incluído o Brasil e não poderia ser diferente em relação às exportações catarinenses. Há também fatores internos que influenciam nesse processo, que podem ser exemplificados pelas diferentes políticas econômicas adotadas conforme a coalizão dominante no poder e apresentadas brevemente, quando se tratou das taxas de câmbio nas diferentes gestões presidenciais. Além disso, há também o fator político que influencia essa dinâmica, como pode ser observado nos dois últimos anos de gestão do governo Dilma, quando ocorreu queda nas exportações em função da crise político-econômica vivenciada pelo país naquele cenário.

Apesar do crescimento gradual das receitas oriundas das exportações catarinenses, de maneira geral houve uma mudança no perfil exportador, tanto em termos de Brasil quanto no tocante a Santa Catarina. Ocorreu um crescimento relativo das exportações de produtos básicos em relação aos produtos industriais, o que corrobora a tese da desindustrialização, tanto na esfera nacional quanto na estadual, conforme é observado na literatura. Rangel (2005) atenta que, por meio do controle do câmbio, o Estado pode impedir a entrada no país de certos bens que o país é capaz de fornecer, promovendo, dessa forma, através de uma política de substituição de importações, o desenvolvimento da indústria nacional.

A partir do governo $\mathrm{FHC}$, as medidas cambiais adotadas levaram o país a um processo de desindustrialização por meio de uma mudança de perfil do comércio exterior catarinense no qual se começou a desenvolver as importações de produtos de baixo valor agregado em detrimento das exportações de produtos de alto valor agregado, conforme observado nas tabelas. Além disso, o dólar subvalorizado prejudica as exportações. Nesse 
sentido torna-se necessária uma política macroeconômica que combine o desenvolvimento do parque fabril, promovendo a produção de produtos com alto valor agregado, alinhado a taxas de câmbio girando em torno da taxa de equilíbrio industrial ou superior, o que permitirá o fortalecimento da indústria e mudança no perfil exportador, e, consequentemente, o desenvolvimento econômico.

Dado o exposto, ao longo do artigo demonstrou-se a influência das taxas de câmbio para o comércio exterior, para as exportações de maneira geral e especialmente para as exportações catarinenses. Lembrou-se também da importância dos fatores externos no processo exportador, como as crises econômicas e de demanda de mercado aquecido por exemplo; e dos fatores internos, como a política econômica, fiscal e monetária, contexto político e perfil dos fatores dos produtos exportados.

Para futuros trabalhos sugere-se o aprofundamento dessa análise para outros estados e regiões brasileiras, efetuando-se diferentes comparações que seriam muito enriquecedoras para as análises, principalmente no tocante ao perfil dos produtos exportados por fatores agregados, relacionando com os diferentes grupos políticos no poder em nível estadual e federal. E por fim, realizar um estudo englobando o Brasil, coletando os dados estaduais, regionais e nacionais e efetuando as comparações e análises.

\section{REFERÊNCIAS}

APEX BRASIL - Agência Brasileira de Promoção de Exportação e Investimentos. Perfil exportador do Estado de Santa Catarina 2010. Brasília: APEX, 2011. Disponível em: www.apexbrasil.com.br/inteligenciaMercado/Downloads?cat=26. Acesso em: 26 mar. 2019.

BANCO CENTRAL DO BRASIL. Taxa de câmbio. Brasília: BCB, 2019. Disponível em: https://www.bcb.gov.br/acessoinformacao/legado?url=https:\%2F\%2Fwww.bcb.gov.br\%2Fpre \%2Fbc_atende\%2Fport\%2FtaxCam.asp. Acesso em: 11 mar. 2019.

BARENHO, Rodrigo Cruvinel. Política comercial do Governo Lula da Silva (2003-2010): preferências dos atores, condicionantes políticos e econômicos e desempenho. 2017. Dissertação (Mestrado em Relações Internacionais) - Universidade de Brasília, Brasília, 2017. Disponível em:

http://repositorio.unb.br/bitstream/10482/23990/1/2017_RodrigoCruvinelBarenho.pdf. Acesso em: 26 jun. 2019.

BRASIL. Ministério do Desenvolvimento, Indústria, Comércio Exterior e Serviços.

Estatísticas de comércio exterior. Brasília: MDICES, 2019. Disponível em: http://www.mdic.gov.br/index.php/comercio-exterior/estatisticas-de-comercio-exterior/comexvis. Acesso em: 14 mar. 2019.

BRESSER-PEREIRA, Luiz Carlos. O governo Dilma frente ao" tripé macroeconômico" e à direita liberal e dependente. Novos Estudos CEBRAP, São Paulo, n. 95, p. 5-15, 2013. Disponível em: http://www.scielo.br/pdf/nec/n95/01.pdf. Acesso em: 14 jun. 2019.

BRESSER-PEREIRA, Luiz Carlos. O novo desenvolvimentismo e a ortodoxia convencional. São Paulo em Perspectiva, São Paulo, v. 20, n. 3, p. 5-24, jul./set. 2006. Disponível em: https://pesquisa-eaesp.fgv.br/sites/gvpesquisa.fgv.br/files/arquivos/bresser__novo_desenvolvimento_e_a_ortodoxia.pdf. Acesso em: 14 jun. 2019. 
BRESSER-PEREIRA, Luiz Carlos. Rangel: ciclos longos e dualidade. São Paulo: FGV, 2012. (Texto para discussão, 318). Disponível em: https://bibliotecadigital.fgv.br/dspace/bitstream/handle/10438/9971/TD\%20318\%20\%20Luiz\%20Carlos\%20Bresser\%20Pereira.pdf. Acesso em: 14 jun. 2019.

CARCANHOLO, Marcelo; PINTO, Eduardo; FILGUEIRAS, Luiz; Reinaldo GONÇALVES, Reinaldo. Crise financeira internacional-natureza e impacto. In: WANSETTO, Rosilene; FURTADO, Fabrina (org.). llegitimidade da dívida pública: quem deve a quem? Alternativas desde o Sul. São Paulo: Expressão Popular, 2008. p. 197-234. Disponível em: http://biblioteca.pacs.org.br/wp-content/uploads/2016/11/PUB_RW-FB_2007_001.pdf. Acesso em: 14 jun. 2019.

CARVALHO, Maria Auxiliadora; SILVA, César Roberto Leite. Mudanças na pauta das exportações agrícolas brasileiras. Revista de Economia e Sociologia Rural, Rio de Janeiro, v. 46, n. 1, p. 53-73, 2008. Disponível em:

http://www.scielo.br/pdf/resr/v46n1/a03v46n1.pdf. Acesso em: 14 jun. 2019.

CLICKRBS. Exportações. Disponível em: http://clicrbs.com.br/pdf/1471626.pdf. Acesso em: 22 mar. 2019.

DEPARTAMENTO INTERSINDICAL DE ESTATÍSTICA E ESTUDOS SOCIOECONÔMICOS - DIEESE. O câmbio e suas influências na economia. Brasília: DIEESE, 2006. (Nota Técnica, n. 24, maio 2006). Disponível em: https://www.dieese.org.br/notatecnica/2006/notatec24cambio.pdf. Acesso em: 26 jun. 2019.

DWECK, Esther; TEIXEIRA, Rodrigo Alves. A política fiscal do governo Dilma e a crise econômica. In: ENCONTRO INTERNACIONAL DA ASSOCIAÇÃO KEYNESIANA BRASILEIRA, 2019, Campinas, SP. Anais [...]. Campinas: Instituto de Economia da UNICAMP, 2019. p. 1-26. Disponível em:

https://even3.blob.core.windows.net/anais/53521.pdf. Acesso em: 24 out. 2020.

ESPÍNDOLA, Carlos José. O impacto geoeconômico da reestruturação tecnico-econômica nas estruturas produtivas catarinenses. Formação (online), Presidente Prudente, v. 25, n. 44, p. 97-117, 2018. Disponível em:

http://revista.fct.unesp.br/index.php/formacao/article/view/5198/4397. Acesso em: 14 jun. 2019.

FEDERAC̣ÃO DAS INDÚSTRIAS DO ESTADO DE SANTA CATARINA - FIESC. Análise do comércio internacional catarinense. Florianópolis: FIESC, 2014. Disponível em: www2.fiescnet.com.br/web/recursos/VUVSR05EWXIPQT09. Acesso em: 22 mar. 2019.

IBGE. Produto interno bruto. Disponível em: https://www.ibge.gov.br/explica/pib.php. Acesso em: 22 out. 2020.

INSTITUTO DE PESQUISA ECONÔMICA APLICADA - IPEA. Taxa de câmbio nominal. Disponível em: http://ipeadata.gov.br/ExibeSerie.aspx?serid=38389. Acesso em: 22 mar. 2019.

MAMIGONIAN, Armen. O mundo no final do século XX e início do século XXI. Boletim Paulista de Geografia, São Paulo, n. 100, p. 173-205, 2018. Disponível em:

https://www.agb.org.br/publicacoes/index.php/boletim-paulista/article/view/1505. Acesso em: 14 jun. 2019.

MARCONI, Nelson; ARAÚJO, Eliane Cristina; OREIRO, José Luis. Taxa de câmbio, elasticidades-renda e mudança estrutural: fundamentos teóricos e evidências empíricas. 2015. Disponível em:

https://cnd.fgv.br/sites/cnd.fgv.br/files/TAXA\%20DE\%20CA\%CC\%82MBIO\%2C\%20ELASTI CIDADES-RENDA\%20E\%20MUDANC\%CC\%A7A\%20ESTRUTURAL_0.pdf. Acesso em: 14 jun. 2019. 
MORAIS, Lecio; SAAD-FILHO, Alfredo. Da economia política à política econômica: o novodesenvolvimentismo e o governo Lula. Brazilian Journal of Political Economy, São Paulo, v. 31, n. 4, p. 507-527, 2011. Disponível em: http://www.scielo.br/pdf/rep/v31n4/01.pdf. Acesso em: 14 jun. 2019.

MORTATTI, Caio Marcos; MIRANDA, Sílvia Helena Galvão; BACCHI, Mirian Rumenos Piedade. Determinantes do comércio Brasil-China de commodities e produtos industriais: uma aplicação VECM. Economia Aplicada, Ribeirão Preto, v. 15, n. 2, p. 311-335, 2011. Disponível em: http://www.scielo.br/pdf/ecoa/v15n2/v15n2a07.pdf. Acesso em: 14 jun. 2019.

PRATES, Daniela Magalhães; FRITZ, Barbara; PAULA, Luiz Fernando. 0 desenvolvimentismo pode ser culpado pela crise? uma classificação das políticas econômica e social dos governos do PT ao governo Temer. 2018. Disponível em: http://www.luizfernandodepaula.com.br/ups/o-desenvolvimentismo-pode-ser-culpado-pelacrise.pdf. Acesso em: 26 mar. 2019.

RANGEL, Ignácio. Obras reunidas. Rio de Janeiro: Contraponto, 2005.

REZENDE, Ricardo Pazzotti. Uma análise das políticas macroeconômicas do governo FHC, governo Lula. 2009. Trabalho de Conclusão de Curso (Graduação em Ciências Econômicas) - Universidade Federal de Santa Catarina, Florianópolis, 2009. Disponível em: http://tcc.bu.ufsc.br/Economia291727. Acesso em: 12 jun. 2019.

ROCHA, Isa de Oliveira. O dinamismo industrial e exportador de Santa Catarina. 2004. Tese (Doutorado em Geografia) - Universidade de São Paulo, São Paulo, 2004.

SANTA CATARINA. Secretaria de Estado do Planejamento. Atlas geográfico de Santa Catarina: estado e território. Florianópolis: UDESC, 2016. Fascículo 1.

Recebido: julho de 2020. Aceito: outubro de 2020.

\footnotetext{
'O presente artigo incorpora reflexões efetuadas na monografia apresentada pela primeira autora ao Departamento de Geografia da Universidade do Estado de Santa Catarina, não publicada.
} 